\title{
Effect of perinatal exposure to Bisphenol-A on DNA methylation and histone acetylation in cerebral cortex and hippocampus of postnatal male mice
}

\author{
Dhiraj Kumar and Mahendra Kumar Thakur \\ Biochemistry and Molecular Biology Laboratory, Brain Research Centre, Institute of Science, \\ Department of Zoology, Banaras Hindu University, Varanasi-221005, India
}

(Received April 15, 2016; Accepted December 14, 2016)

\begin{abstract}
Bisphenol-A (BPA) is an estrogenic endocrine disruptor mostly used for the production of polycarbonate plastics and epoxy resins. Recently we have reported that perinatal BPA exposure impaired spatial memory through upregulation of synaptic proteins Neurexin1 and Neuroligin 3 in male mice. As epigenetic mechanism is a key regulator of memory, we hypothesized that BPA might influence memory through epigenetic regulation of gene expression. Here we provide evidence that perinatal exposure to BPA decreased 5-mC DNA but increased histone $\mathrm{H} 3$ acetylation in cerebral cortex and hippocampus of postnatal 3 and 8 weeks male mice. BPA exposure also increased mRNA levels of DNMT1 and DNMT3a in cerebral cortex of 3 and 8 weeks; whereas in hippocampus DNMT1 mRNA increased in 3 weeks but decreased in 8 weeks and DNMT3a showed no change. Further, HDAC2 mRNA and protein increased in cerebral cortex of both ages and in hippocampus it increased in 3 weeks but decreased in 8 weeks. Altogether, our results demonstrate that the perinatal BPA exposure induces epigenetic changes that possibly underlie the enduring effect of BPA on brain function and behavior.
\end{abstract}

Key words: Bisphenol-A, Histone acetylation, DNA methylation

\section{INTRODUCTION}

Bisphenol-A (BPA) attracts major concern today due to its ubiquitous presence in the environment and thus exposure to humans and wildlife (Vandenberg et al., 2010). Developmental exposure to BPA in rodents showed negative impact on fertility, reproduction, behavior and increasing risk of obesity (Migliarini et al., 2011; Walker and Gore, 2011; Wolstenholme et al., 2012; Nagao et al., 2014). The developing brain is highly sensitive to the changes of environmental conditions such as maternal care, stress and exposure to toxic compounds (Ansorge et $a l ., 2007)$. Among the environmental chemicals with neurotoxic potential, BPA is the main source as an estrogenic toxin used mainly for the manufacturing of polycarbonate plastics and epoxy resins (Suzuki et al., 2000). We have earlier reported that perinatal exposure to BPA impaired spatial memory in postnatal male mice through upregulation of synaptic proteins Neurexin1 and Neuroligin3 (Kumar and Thakur, 2014). BPA elicits its action through steroid hormone receptors and alters the hormone synthe- sis and clearance (Zhou et al., 2008). Such change in hormone levels is known to alter the epigenetic mechanisms such as DNA methylation and histone modifications (Bromer et al., 2010). Therefore, it is likely that perinatal BPA exposure might influence memory through epigenetic modifications.

Increasing evidences implicate the role of epigenetics in mediating gene-environment interactions and dynamic changes in DNA methylation are known to regulate the tissue and cell type-specific gene expression during vertebrate development (Barresi et al., 1999; Boatright et al., 2000; Feil and Fraga, 2012; Weaver et al., 2009). Also the post-translational modification of core histone proteins (H2A, H2B, H3 and H4), especially histone tail acetylation, is involved in modulation of transcription and memory formation (Swank and Sweatt, 2001; Korzus et al., 2004; Wood et al., 2005). Such epigenetic gene regulation processes are particularly sensitive to environmental cues during development (Reik, 2007). In rodents, the maternal exposure to stress and endocrine disruptor during pregnancy can modify the epigenetic gene programming

Correspondence: Mahendra Kumar Thakur (E-mail: mkt_bhu@yahoo.com) 
and contribute to neurodevelopmental deficits in offspring (Skinner et al., 2008). Following low dose maternal BPA exposure, the genome-wide $\mathrm{CpG}$ methylation has been studied in mouse forebrain during embryonic stages 12.5 and 14.5 (Yaoi et al., 2008), though the underlying enzymes, histone acetylation and its long term consequences have not been explored. Therefore, in the present study, we have analyzed the effect of perinatal exposure to BPA on the level of DNA methylation, expression of epigenetic regulators DNA methyltransferase (DNMT1 and DNMT3a), histone acetylation (H3K9 and H3K14) and histone deacetylase2 (HDAC2) in the cerebral cortex and hippocampus of postnatal 3 and 8 weeks male mice.

\section{MATERIALS AND METHODS}

\section{Animals}

The inbred Swiss albino mice colony was maintained in the animal house of Department of Zoology, Banaras Hindu University, Varanasi, India at a $12 \mathrm{hr}$ light-dark cycle and stable conditions of temperature $\left(25 \pm 2{ }^{\circ} \mathrm{C}\right)$ with free access to soy-free diet (Amrut laboratory animals diet, Pune, India) and water in glass bottle. Adult male and female mice were kept for mating (female:male, $2: 1$ ) in the evening and the vaginal plug was observed daily in the morning. Plug positive mice were kept in separate BPA free cages (one mouse/cage) and designated as gestational day (GD) 0 . After a week, ten mice were exposed to BPA and another ten were administered sesame oil as vehicle control. All the experiments were conducted in accordance with the Care and Use Standard of the Institutional Animal Ethical Committee, Banaras Hindu University, Varanasi, India.

\section{Treatment}

The pregnant mice were orally administered BPA (99.8\% pure, Sigma-Aldrich, St. Louis, MO, USA) dissolved in sesame oil $(50 \mu \mathrm{g} / \mathrm{kgbw} / \mathrm{d})$ by oral gavages from gestational day 7 (GD 7) to postnatal day 21 (PND21) with care to avoid hassle as described earlier (Kumar and Thakur, 2014). The control mice were administered only sesame oil for the same duration. Separate needles were used to avoid unintended exposure to BPA. Treatment was administered between 8:30 am to 9:30 am dai1y. The pups were weaned on PND21 and housed in separate cages. The cerebral cortex and hippocampus of 3 and 8 weeks postnatal male mice ( $\mathrm{n}=3 \times 3$ mice/group) were dissected out for analyzing the level of 5-mC DNA and expression of DNMT1, DNMT3a, H3K9, H3K14 and HDAC2.

\section{Slot blot analysis of 5- methylcytosine (5-mC)}

The level of 5- methylcytosine (5-mC) DNA was analyzed as described earlier (Nandakumar et al., 2011). Briefly, genomic DNA was isolated using the DNA isolation kit (Qiagen Sciences, Redwood City, CA, USA) according to the manufacturer's instructions. The amount of DNA was estimated using a spectrophotometer and $5 \mu \mathrm{g}$ DNA was transferred onto a positively charged Hybond nitrocellulose membrane (Amersham Biosciences, Buckinghamshire, UK) using slot blot apparatus (S\&S Minifold II, Schleicher \& Schuell, USA). The DNA on membrane was fixed by UV light exposure. After blocking the non-specific binding sites, the membrane was incubated with the antibody specific to $5-\mathrm{mC}$ (1:500, Epigentek-33D3) followed by incubation with horseradish peroxidase-conjugated secondary anti mouse antibody (1:2000, Bangalore Genei, Bangalore, India). The membrane was then treated with enhanced chemiluminescence detection reagents (Western Bright, Advansta, Optical Ave, Keene, NH, USA) and exposed to Kodak $\mathrm{X}$-ray films. The membrane was also stained with $0.2 \%$ methylene blue to verify equal amount of DNA loading. The intensity of signal on the autoradiogram and membrane was measured by densitometry analysis tool of Alpha Ease software (Alpha Innotech Corp., Santa Clara, CA, USA) and relative density value (RDV) was determined.

\section{RT-PCR}

Total RNA was isolated from the cerebral cortex and hippocampus of 3 and 8 weeks postnatal male mice using the TRI Reagent kit (Sigma-Aldrich) according to manufacturer's protocol. The amount of RNA was estimated by taking absorbance at $260 \mathrm{~nm}$ and RNA sample with $\mathrm{A}_{260 / 280}$ of 1.8 was used. It was resolved on $1.2 \%$ agarose formaldehyde gel to check its integrity by ethidium bromide staining of $28 \mathrm{~S}$ and $18 \mathrm{~S}$ rRNA. For cDNA synthesis, $3 \mu \mathrm{g}$ of total RNA and $200 \mathrm{ng}$ random hexamer (Fermentas International Inc., Viwnius, Canada) were mixed in $11 \mu \mathrm{L}$ reaction volume and denatured at $70^{\circ} \mathrm{C}$ for $5 \mathrm{~min}$. Further, $2 \mu \mathrm{L}$ of $10 \mathrm{x}$ reaction buffer, $2 \mu \mathrm{L}$ of $10 \mathrm{mM}$ dNTPs mix and $20 \mathrm{U}$ of RNase inhibitor (New England Biolabs, Ipswich, MA, USA) were added, the volume was made to $19 \mu \mathrm{L}$ and incubated at $25^{\circ} \mathrm{C}$ for $5 \mathrm{~min}$. Thereafter, $200 \mathrm{U}$ of M-MuLv reverse transcriptase (New England Biolabs, USA) was added and the tube was incubated first at $25^{\circ} \mathrm{C}$ for $10 \mathrm{~min}$ and then at $42^{\circ} \mathrm{C}$ for $1 \mathrm{hr}$ in a thermal cycler (Applied Biosystem, Waltham, MA, USA). The reaction was stopped by heating at $70^{\circ} \mathrm{C}$ for 10 min and cDNA was stored at $-80^{\circ} \mathrm{C}$. The cDNA was used for RT-PCR amplification of DNMT1, DNMT3a 
Effect of perinatal exposure to BPA on epigenetic modification

Table 1. Primer sequences and RT-PCR condition.

\begin{tabular}{|c|c|c|c|c|}
\hline Gene & Forward $(\mathrm{F})$ and reverse $(\mathrm{R})$ primers & $\begin{array}{c}\text { Annealing } \\
\text { temperature }\left({ }^{\circ} \mathrm{C}\right)\end{array}$ & No. of cycle & $\begin{array}{l}\text { Amplicon } \\
\text { size (bp) }\end{array}$ \\
\hline DNMT1 & $\begin{array}{l}\text { F-5'CCTAGTTCCGTGGCTACGAGGAGAA3' } \\
\text { R-5'TCTCTCTCCTCTGCAGCCGACTCA3' }\end{array}$ & 58 & 26 & 137 \\
\hline DNMT3a & $\begin{array}{l}\text { F-5'CCGAATTGTGTCTTGGTGGATGACA3' } \\
\text { R-5'CCTGGTGGAATGCACTGCAGAAGGA3' }\end{array}$ & 59 & 26 & 147 \\
\hline HDAC2 & $\begin{array}{l}\text { F-5'GGTCGTAGGAATGTTGCTGAT3' } \\
\text { R-5'AAGCCAATGTCCTCAAACAGG3', }\end{array}$ & 61 & 28 & 257 \\
\hline GAPDH & $\begin{array}{l}\text { F-5'GTCTCCTGCGACTTCAG3' } \\
\text { R-5'TCATTGTCATACCAGGAAATGAGC3' }\end{array}$ & 52 & 26 & 108 \\
\hline
\end{tabular}

and HDAC2. The details of primer sequences and conditions are given in Table 1 . The PCR amplicons were run in $2 \%$ agarose gel and photo was taken using gel documentation system. The band intensity of internal control and genes were analyzed by spot densitometry tool of Alpha Ease FC software (Alpha Innotech Corp.) as described earlier (Kumar and Thakur, 2014).

\section{Immunoblotting}

The immunoblotting was performed as described earlier (Zhang et al., 2014). Briefly, the cerebral cortex and hippocampus of 3 and 8 weeks male mice were homogenized in ice-cold RIPA buffer containing $1 \%$ Triton $\mathrm{X}-100,1 \%$ deoxycholate, $0.1 \%$ SDS and $1 \mathrm{mM}$ PMSF. The homogenate was centrifuged at $14,000 \mathrm{x} g$ for $10 \mathrm{~min}$ at $4^{\circ} \mathrm{C}$. The supernatant was used for the immunoblotting analysis of HDAC2 and pellet was used for the isolation of histone rich fraction.

The pellet (nuclear fraction) was resuspended in $200 \mu \mathrm{L}$ of $0.25 \mathrm{M} \mathrm{HCl}$ and kept at $4^{\circ} \mathrm{C}$ overnight to extract histone. Next day, the nuclear fraction was centrifuged at $14,000 \times \mathrm{g}$ for $10 \mathrm{~min}$ at $4^{\circ} \mathrm{C}$. The supernatant (histone extract) was mixed with loading buffer after neutralization of $\mathrm{HCl}$ with $2.5 \mathrm{M} \mathrm{NaOH}$ and boiled for $5 \mathrm{~min}$. It was separated by SDS-PAGE and processed for the immunoblotting analysis of $\mathrm{H} 3 \mathrm{~K} 9$ and H3K14.

The amount of protein was determined using Bradford method and $30 \mu \mathrm{g}$ protein from each sample was loaded and run on a $4 \%$ stacking gel with $10 \%$ (HDAC2 and $\beta$-Actin) or $15 \%(\mathrm{H} 3 \mathrm{~K} 9, \mathrm{H} 3 \mathrm{~K} 14$ and $\mathrm{H} 3)$ resolving polyacrylamide gel. After electrophoresis, the protein was transferred onto polyvinylidene fluoride (PVDF) membrane (Millipore, Billerica, MA, USA) using semidry transfer apparatus (Pharmacia Biotech, Piscataway, NJ, USA). The membrane was incubated in blocking buffer $\left(5 \%\right.$ fat-free milk in $1 \mathrm{x}$ PBS) for $2 \mathrm{hr}$ at $37^{\circ} \mathrm{C}$ to block nonspecific binding sites. Further, the membrane was incubated overnight at $4^{\circ} \mathrm{C}$ in primary antibody [anti H3K9- 1:1000 (Millipore-06942), anti H3K14- 1:1000
(Epigentek-06-942) and anti HDAC2- 1:5000 (SigmaAldrich)]. After washing three times in PBS, each $5 \mathrm{~min}$, the membrane was incubated in specific secondary antibody, horseradish peroxidase-conjugated IgG (1:2000) for $3 \mathrm{hr}$ at room temperature. $\beta$-Actin was used as an internal control for HDAC2 and $\mathrm{H} 3$ for $\mathrm{H} 3 \mathrm{~K} 9$ and H3K14. Finally, the membrane was washed with PBS three times, each $5 \mathrm{~min}$. The bands were detected by ECL method (Western Bright, Advansta, Menlo Park, CA, USA) on X-rays film and the band intensity was analyzed by spot densitometry tool of Alpha Ease FC software (Alpha Innotech Corp.).

\section{Statistical analysis}

All molecular data were analyzed by one-way ANOVA followed by Tukey test in SPSS statistics (version 16) for all parameters. The band intensity of RT-PCR and immunoblotting results were analyzed by spot densitometry tool of Alpha Ease FC software (Alpha Innotech Corp.) as described earlier (Kumar and Thakur, 2015). Briefly, the RT-PCR band intensity was normalized against internal control GAPDH and immunoblotting by $\beta$-Actin. The average relative density values from three independent experiments were used for plotting the histograms. All the values were reported as mean \pm S.E.M. $(n=3 \times 3$ mice per group) and $\mathrm{p}$ value $<0.05$ was considered as statistically significant.

\section{RESULTS}

\section{Perinatal exposure to BPA decreased 5-mC DNA}

In order to examine the effect of perinatal exposure to BPA on DNA methylation, slot blot analysis was performed using anti 5-mC antibody. As compared to vehicle control, a significant decrease in 5-mC DNA methylation was noted in cerebral cortex and hippocampus of perinatally BPA rendered 3 weeks ( $57 \%$ in cerebral cortex and $68 \%$ in hippocampus) and 8 weeks (43\% in cerebral cortex and $53 \%$ in hippocampus) in male mice (Fig. 1). The extent of hypomethylation was greater in 3 weeks as com- 

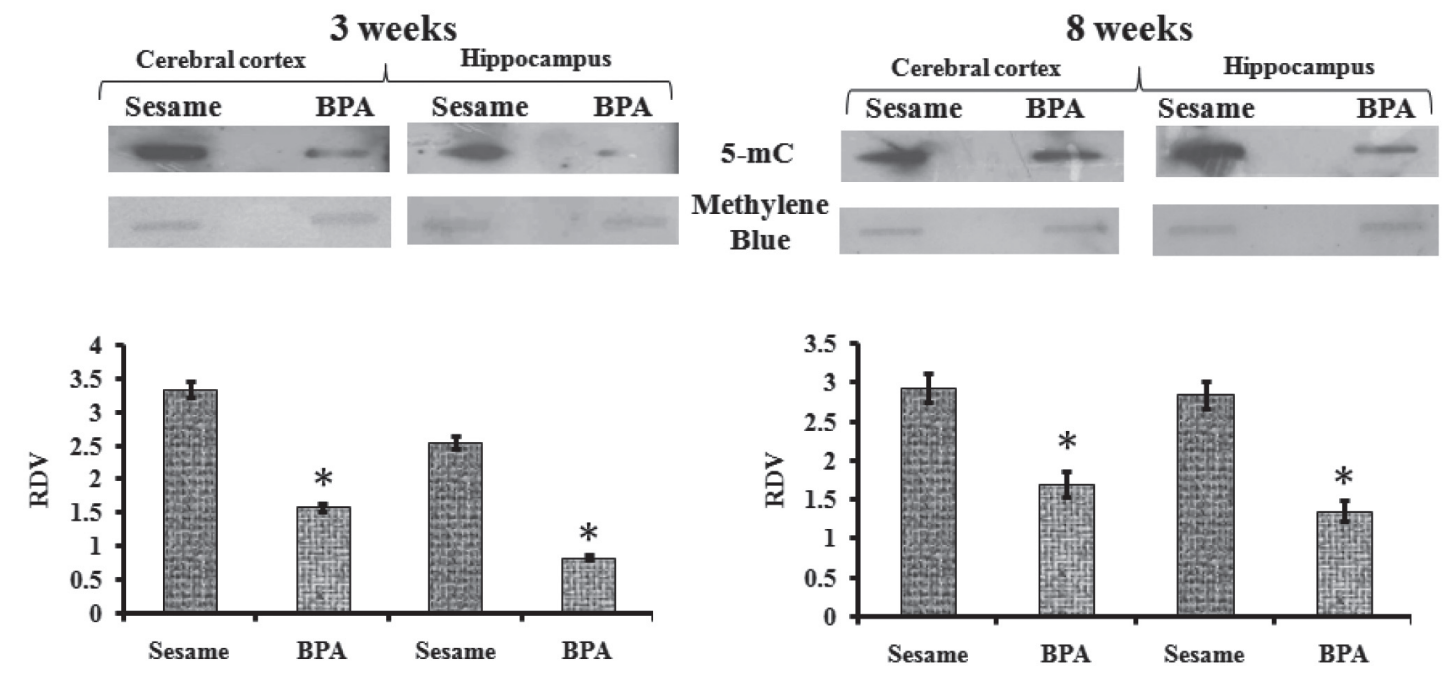

Fig. 1. Effect of perinatal exposure to BPA on 5-mC DNA in the cerebral cortex and hippocampus of 3 and 8 weeks postnatal male mice. Methylene blue staining of membrane represents the equal DNA loading. The results are expressed as the mean \pm S.E.M. and * denotes the significant difference $(\mathrm{p}<0.05)$ between sesame oil- and BPA- exposed mice.

pared to 8 weeks. Moreover, methylation level continued to decrease in 8 weeks male mice even after withdrawal of BPA exposure at 3 weeks.

\section{Perinatal exposure to BPA altered DNMT mRNA}

As compared to vehicle control, DNMT1 expression increased in cerebral cortex of postnatal 3 weeks (43\%) and 8 weeks (32\%) male mice. However, in hippocampus, DNMT1 increased in 3 weeks (27\%) but decreased in 8 weeks (19\%) as compared to vehicle control (Fig. 2A). Furthermore, DNMT3a showed increased expression only in cerebral cortex of 3 weeks (34\%) and 8 weeks (27\%) but remained unchanged in hippocampus of mice of both ages (Fig. 2B).

\section{Perinatal exposure to BPA increased acetylation of H3K9 and H3K14}

In order to evaluate the long term impact of BPA exposure, the acetylation of histone H3K9 and H3K14 was analyzed in 3 weeks (when exposure was refrained) and 8 weeks mice. The acetylation of $\mathrm{H} 3 \mathrm{~K} 9$ significantly increased in cerebral cortex ( $48 \%$ in 3 and 8 weeks) and hippocampus ( $33 \%$ in 3 and 8 weeks) of postnatal male mice (Fig. 3A). Similarly, H3K14 acetylation increased in cerebral cortex (35\% in 3 weeks and $40 \%$ in 8 weeks) and in hippocampus (38\%) of mice of both ages (Fig. 3B). Thus, the perinatal exposure increases $\mathrm{H} 3$ acetylation in BPA rendered postnatal male mice.

\section{Perinatal exposure to BPA altered HDAC2 mRNA and protein}

In order to evaluate the impact of perinatal BPA exposure on HDAC2 expression, RT-PCR and immunoblotting was performed in postnatal male mice as described earlier (Singh and Thakur, 2014). Perinatally BPA-exposed mice showed significantly high level of HDAC2 mRNA expression in cerebral cortex (78\% in 3 and $48 \%$ in 8 weeks). However, in hippocampus, HDAC2 mRNA expression increased $52 \%$ in 3 weeks but decreased $31 \%$ in 8 weeks as compared to vehicle control (Fig. 4A). The RT-PCR data corresponded with immunoblotting results (Fig. 4B).

\section{DISCUSSION}

The present study investigated the impact of perinatal BPA exposure on DNA methylation and histone acetylation in postnatal male mice. The 5-mC DNA decreased but $\mathrm{H} 3$ acetylation (H3K9 and $\mathrm{H} 3 \mathrm{~K} 14)$ increased in cerebral cortex and hippocampus of postnatal male mice. Also, the enzymes DNMT1, DNMT3a and HDAC2 showed altered expression following exposure to BPA. Interestingly, the alterations mediated by perinatal BPA exposure during development persisted even after the withdrawal of exposure.

Perinatal BPA exposure significantly decreased the 5-mC DNA in cerebral cortex and hippocampus of postnatal male mice. DNA methylation is influenced by sev- 
A
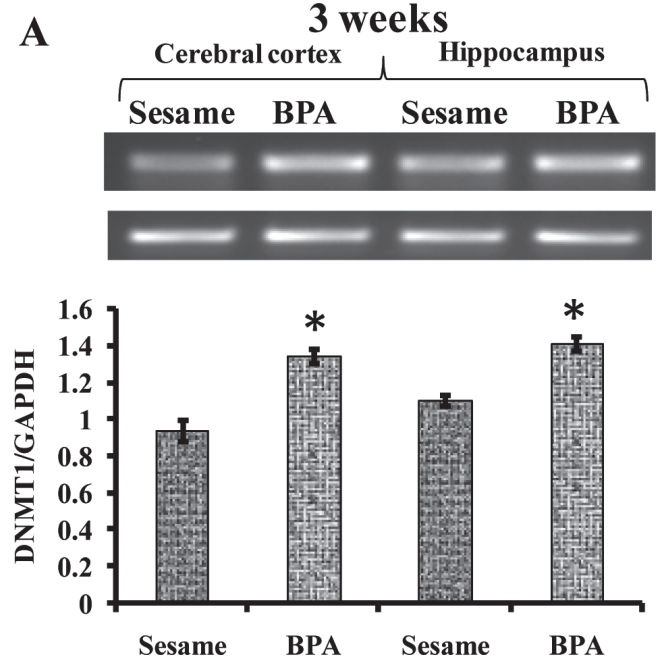

3 weeks

B
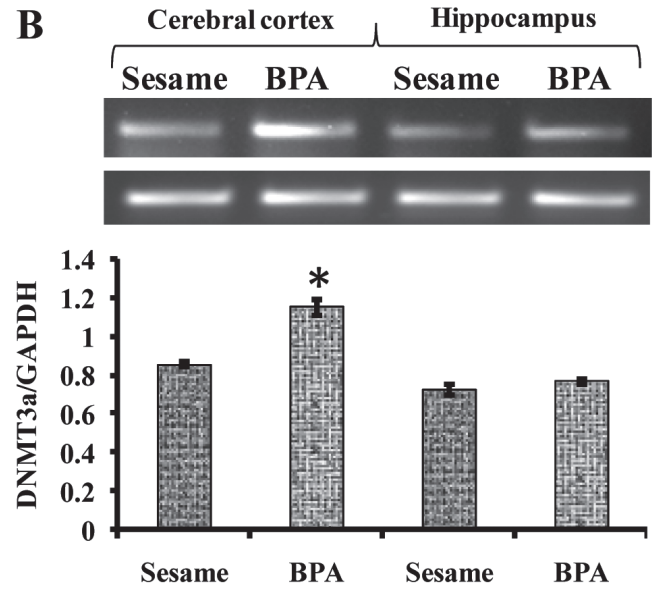

8 weeks
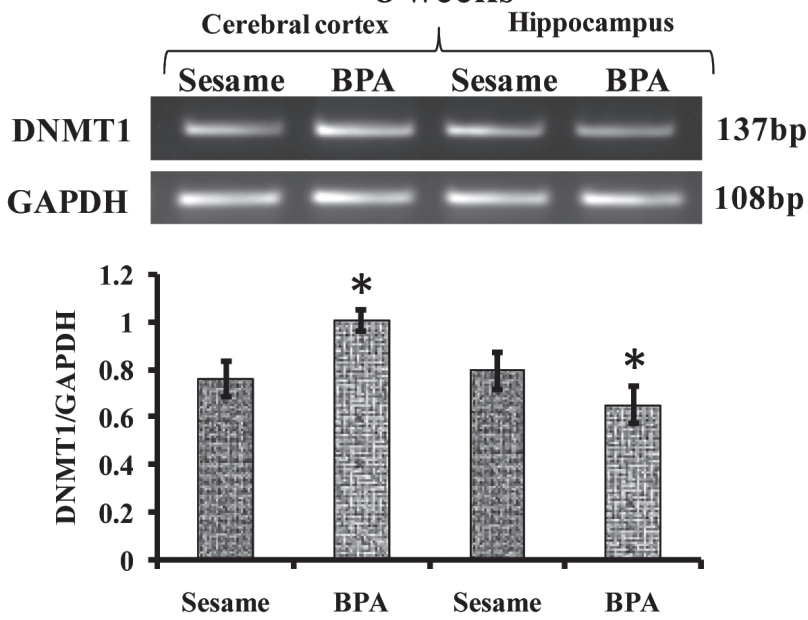

8 weeks

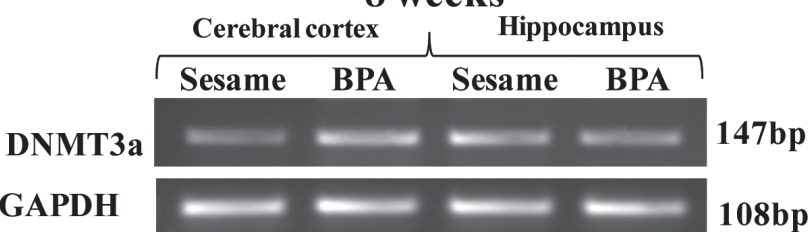

Fig. 2. Effect of perinatal exposure to BPA on the expression of DNMT1 (A) and DNMT3a (B) in the cerebral cortex and hippocampus of postnatal 3 and 8 weeks male mice. The results are expressed as the mean \pm S.E.M. and * denotes the significant difference $(\mathrm{p}<0.05)$ between sesame oil- and BPA- exposed mice.

eral environmental chemical insults including BPA during development (Dolinoy et al., 2007). Furthermore, the epigenetic changes are reported to involve in the etiology of several neurological disorders (Lahiri et al., 2009). In particular, the paradigm shift of epigenetics is involved in Alzheimer's disease (Zawia and Lahiri, 2012). Patel et al (2013) reported that lifelong exposure to BPA altered the cardiac structure and resulted in the global level hypermethylation in male and hypomethylation in postnatal female mouse heart. Furthermore, neonatal BPA exposure led to gene specific methylation in phosphoesterase type 4 variant 4 , nuclosome binding protein-1 (Tang et al., 2012), HoxA 10 (Bromer et al., 2010) and hippocal- cin-like 1 (Tang et al., 2012). Our previous study reported that perinatal exposure to BPA impaired spatial memory through upregulation of Neurexin1 and Neuroligin3 expression in postnatal male mice (Kumar and Thakur, 2014). Therefore, it is likely that BPA exposure might be involved in hypomethylation of promoter of these genes and thereby increase their expression. However, only gene specific study can corroborate such speculation. Taken together, 5-mC analysis results indicate that developmental BPA exposure decreases the 5-mC DNA in postnatal male mice and might be implicated in impaired memory.

The methylation level of genome is regulated by the epigenetic regulator, DNA methyltransferases, which are 

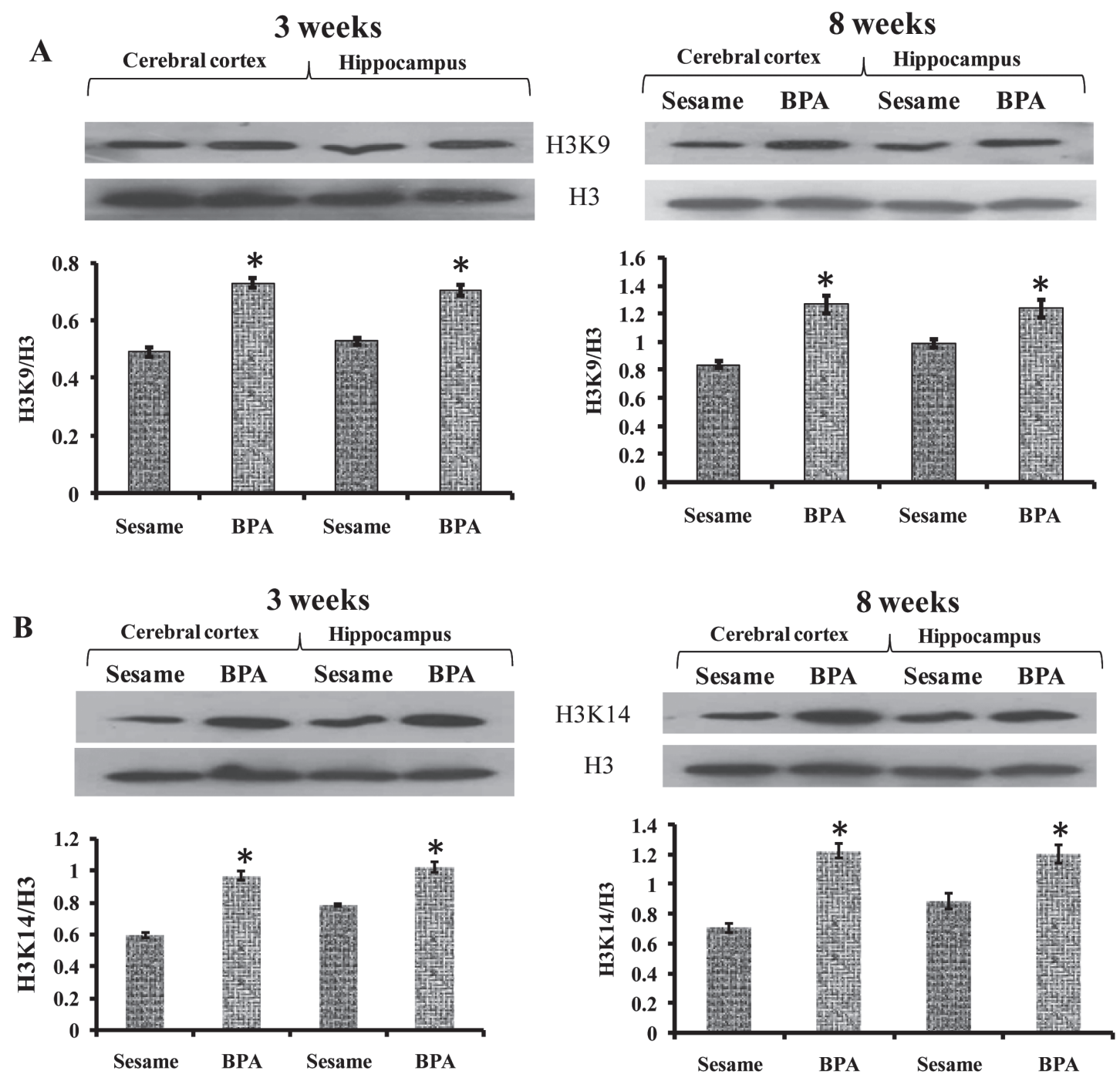

Fig. 3. Effect of perinatal exposure to BPA on H3K9 (A) and H3K14 (B) acetylation in the cerebral cortex and hippocampus of postnatal 3 and 8 weeks male mice. The results are expressed as the mean \pm S.E.M. and * denotes the significant difference $(\mathrm{p}<0.05)$ between sesame oil- and BPA- exposed mice.

expressed predominantly in the brain (Feng et al., 2005). The deletion of DNMT1 and DNMT3a in the forebrain of mature neurons decreased DNA methylation, altered gene expression and caused abnormal long-term hippocampal plasticity and memory deficits (Feng et al., 2010). In the present study, perinatal BPA exposure resulted in increased DNMT1 expression in cerebral cortex of both 3 and 8 weeks, whereas hippocampal DNMT1 expression increased in 3 weeks and decreased in 8 weeks. Further, DNMT3a expression increased in cerebral cortex of both 3 and 8 weeks, but remained unchanged in hippocampus of 3 and 8 weeks. Furthermore, the manipula- tion of DNMT3a levels in the adult nucleus accumbens affected the global level DNA methylation and emotional behavior (LaPlant et al., 2010). BPA exposure during neonatal stages also altered the expression of DNMT3a/b in prostate gland of postnatal rat (Tang et al., 2012). Further, lifelong BPA exposure in mice increased DNMT3a and decreased DNMT3b expression in the heart of postnatal mice (Patel et al., 2013). Thus, our observation suggests that perinatal exposure to BPA induces long-lasting epigenetic changes which might affect gene expression and contribute to BPA induced impairment of memory.

The modification of chromatin is dynamic process and 
Effect of perinatal exposure to BPA on epigenetic modification

A 3 weeks
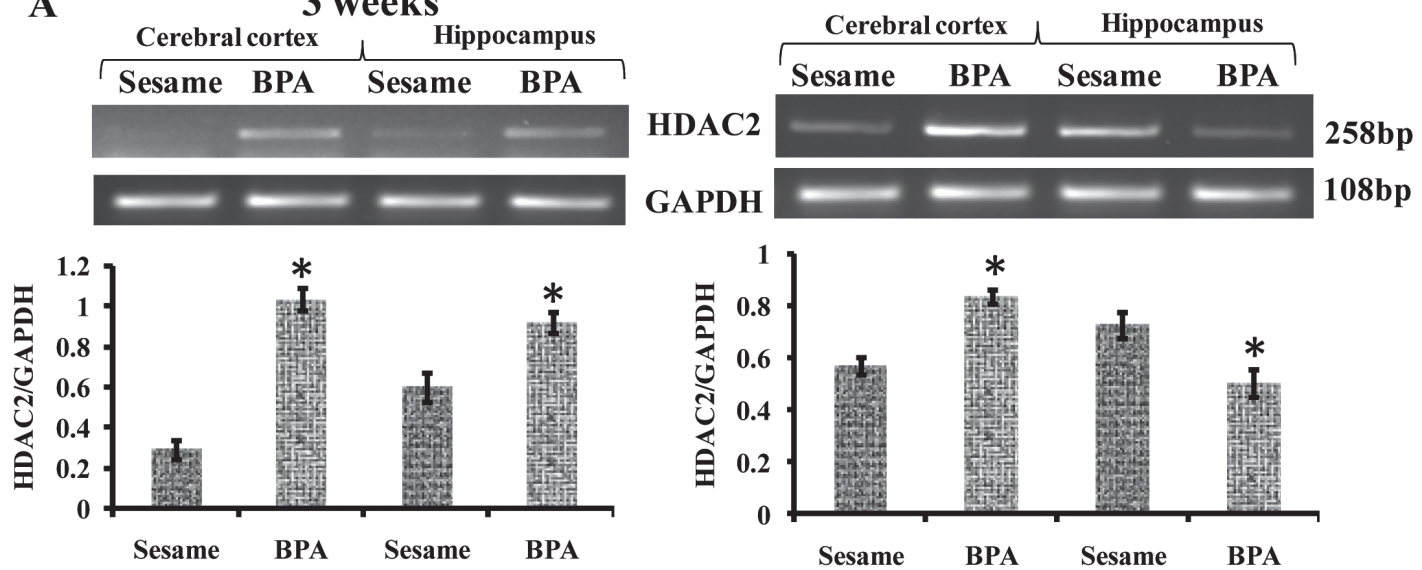

B

3 weeks
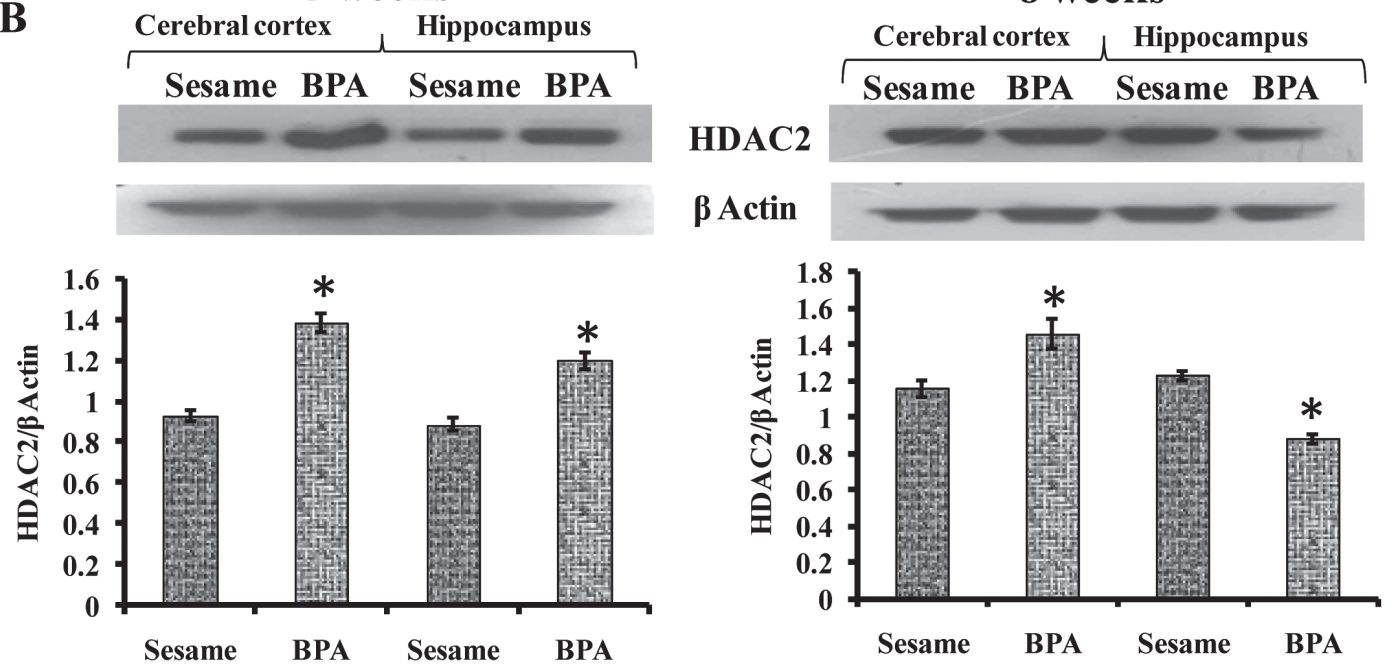

Fig. 4. Effect of perinatal exposure to BPA on the expression of HDAC2, RT-PCR (A) and immunoblotting (B) in the cerebral cortex and hippocampus of postnatal 3 and 8 weeks male mice. The results are expressed as the mean \pm S.E.M. and $*$ denotes the significant difference $(\mathrm{p}<0.05)$ between sesame oil- and BPA- exposed mice.

primarily regulated through histone acetyltransferases and deacetylases (HDACs). A balance between the activities of these enzymes is a principal regulator of gene expression. The acetylation of histone tail neutralizes the basic charge on lysine residues and thus triggers the unfolding of chromatin and invariably allows transcription activity (Kimura et al., 2005; Choi and Howe, 2009). We observed significant increase in the acetylation of H3K9 and H3K14 in both cerebral cortex and hippocampus of postnatal male mice. Also, exposure to BPA in adulthood for 90 days increased H3K9 and H3K14 acetylation after fear conditioning in the hippocampus of male mice (Zhang et al., 2014). Several studies indicate that histone acetylation-deacetylation in neurons is associated with the process of learning and memory (Kurdistani and Grunstein, 2003; Kumar et al., 2005; Chwang et al., 2006; Goldberg et al., 2007; Lubin and Sweatt, 2007; Peixoto and Abel, 2013). Moreover, our study showed that increased acetylation level persisted in 8 weeks postnatal mice even after withdrawal of BPA exposure, suggesting the involvement of BPA exposure in mediating long lasting impact on histone acetylation and consequently impaired memory.

The environmental factors play a pivotal role in the 


\section{Kumar and M.K. Thakur}

establishment and maintenance of epigenetic modifications. Animal studies reported that nutrition and environmental exposure during development can alter the epigenome. In particular, studies in mice revealed noticeable differences in epigenetic responses to environmental factors between inbreed strains (Rosenfeld, 2010). Thus, the present study suggests that the perinatal exposure to BPA, an environmental toxin affects memory of postnatal male mice through decrease in global level 5-mC DNA and increase in $\mathrm{H} 3$ acetylation by modulating the expression of underlying enzymes (DNMT1, DNMT3a and HDAC2).

\section{ACKNOWLEDGMENTS}

This work was supported by grants from the Department of Biotechnology, Government of India, to MK Thakur [BT/PR3996/MED/97/57/2011]. The Council of Scientific Industrial Research, India, is acknowledged for providing junior and senior research fellowship to Dhiraj Kumar [09/013(0253)/2009-EMR-I].

Conflict of interest---- The authors declare that there is no conflict of interest.

\section{REFERENCES}

Ansorge, M.S., Hen, R. and Gingrich, J.A. (2007): Neurodevelopmental origins of depressive disorders. Curr. Opin. Pharmacol., 7, 8-17.

Barresi, V., Condorelli, D.F. and Giuffrida Stella, A.M. (1999): GFAP gene methylation in different neural cell types from rat brain. Int. J. Dev. Neurosci., 17, 821-828.

Boatright, J.H., Nickerson, J.M. and Borst, D.E. (2000): Site-specific DNA hypomethylation permits expression of the IRBP gene. Brain Res., 887, 211-221.

Bromer, J.G., Zhou, Y., Taylor, M.B., Doherty, L. and Taylor, H.S. (2010): Bisphenol-A exposure in utero leads to epigenetic alterations in the developmental programming of uterine estrogen response. FASEB J., 24, 2273-2280.

Choi, J.K. and Howe, L.J. (2009): Histone acetylation: truth of consequences? Biochem. Cell Biol., 87, 139-150.

Chwang, W.B., O'Riordan, K.J., Levenson, J.M. and Sweatt, J.D. (2006): ERK/MAPK regulates hippocampal histone phosphorylation following contextual fear conditioning. Learn. Mem., 13, 322-328.

Dolinoy, D.C., Huang, D. and Jirtle, R.L. (2007): Maternal nutrient supplementation counteracts bisphenol A-induced DNA hypomethylation in early development. Proc. Natl. Acad. Sci. USA., 104, 13056-13061.

Feng, J., Chang, H., Li, E. and Fan, G. (2005): Dynamic expression of de novo DNA methyltransferases Dnmt3a and Dnmt3b in the central nervous system. J. Neurosci. Res., 79, 734-746.

Feil, R and Fraga, M.F. (2012): Epigenetics and the environment: emerging patterns and implications. Nat. Rev. Genet., 13, 97-109.
Feng, J., Zhou, Y., Campbell, S.L., Le, T., Li, E., Sweatt, J.D., Silva, A.J. and Fan, G. (2010): Dnmt1 and Dnmt3a maintain DNA methylation and regulate synaptic function in adult forebrain neurons. Nat. Neurosci., 13, 423-430.

Gallou-Kabani, C, Gabory, A., Tost, J., Karimi, M., Mayeur, S., Lesage, J., Boudadi, E., Gross, M.S., Taurelle, J., Vigé, A., Breton, C., Reusens, B., Remacle, C., Vieau, D, Ekström, T.J., Jais, J.P. and Junien, C. (2010): Sex- and diet-specific changes of imprinted gene expression and DNA methylation in mouse placenta under a high-fat diet. PLoS ONE, 5, e14398.

Goldberg, A.D., Allis, C.D. and Bernstein, E. (2007): Epigenetics: a landscape takes shape. Cell, 128, 635-638.

Kimura, A., Matsubara, K. and Horikoshi, M. (2005): A decade of histone acetylation: marking eukaryotic chromosomes with specific codes. J. Biochem., 138, 647-662.

Korzus, E., Rosenfeld, M.G. and Mayford, M. (2004): CBP histone acetyltransferase activity is a critical component of memory consolidation. Neuron, 42, 961-972.

Kumar, A., Choi, K.H., Renthal,W., Tsankova, N.M., Theobald, D.E., Truong, H.T., Russo, S.J., Laplant, Q., Sasaki, T.S., Whistler, K.N., Neve, R.L., Self, D.W. and Nestler, E.J. (2005): Chromatin remodeling is a key mechanism underlying cocaineinduced plasticity in striatum. Neuron, 48, 303-314.

Kumar, D. and Thakur, M.K. (2014): Perinatal Exposure to Bisphenol-A Impairs Spatial Memory through Upregulation of Neurexin1 and Neuroligin3 Expression in Male Mouse Brain. PLoS ONE, 9, e110482.

Kumar, D. and Thakur, M.K. (2015): Age-related expression of Neurexin 1 and Neuroligin 3 is correlated with presynaptic density in the cerebral cortex and hippocampus of male mice. Age, $37,17$.

Kurdistani, S.K. and Grunstein, M. (2003): Histone acetylation and deacetylation in yeast. Nat. Rev. Mol. Cell Biol., 4, 276-284.

Lahiri, D.K., Maloney, B. and Zawia, N.H. (2009): The LEARn model: an epigenetic explanation for idiopathic neurobiological diseases. Mol. Psychiatry, 14, 992-1003.

LaPlant, Q., Vialou, V., Covington, H.E.3rd., Dumitriu, D., Feng, J., Warren, B.L., Maze, I., Dietz, D.M., Watts, E.L., Iñiguez, S.D., Koo, J.W., Mouzon, E., Renthal, W., Hollis, F., Wang, H., Noonan, M.A., Ren, Y., Eisch, A.J., Bolaños, C.A., Kabbaj, M., Xiao, G., Neve, R.L., Hurd, Y.L., Oosting, R.S., Fan, G., Morrison, J.H. and Nestler, E.J. (2010): Dnmt3a regulates emotional behavior and spine plasticity in the nucleus accumbens. Nat Neurosci., 13, 1137-1143.

Lubin, F.D. and Sweatt, J.D. (2007): The IkappaB kinase regulates chromatin structure during reconsolidation of conditioned fear memories. Neuron, 55, 942-957.

Migliarini, B., Piccinetti, C. C., Martella, A., Maradonna, F., Gioacchini, G. and Carnevali, O. (2011): Perspectives on endocrine disruptor effects on metabolic sensors. Gen. Comp. Endocrinol., 170, 416-423.

Nagao, T., Kawachi, K., Kagawa, N. and Komada, M. (2014): Neurobehavioral evaluation of mouse newborns exposed prenatally to low-dose bisphenol A. J. Toxicol. Sci., 39, 231-235.

Nandakumar, V., Vaid, M. and Katiyar, S.K. (2011): (-)-Epigallocatechin-3-gallate reactivates silenced tumor suppressor genes, Cip1/ p21 and p16INK4a, by reducing DNA methylation and increasing histones acetylation in human skin cancer cells. Carcinogenesis, 32, 537-544.

Patel, B.B., Raad, M., Sebag, I.A. and Chalifour, L.E. (2013): Lifelong exposure to bisphenol a alters cardiac structure/function, protein expression, and DNA methylation in adult mice. Toxicol. 
Effect of perinatal exposure to BPA on epigenetic modification

Sci, 133, 174-185

Peixoto, L. and Abel, T. (2013) The role of histone acetylation in memory formation and cognitive impairments. Neuropsychopharmacology, 38, 62-76.

Reik, W. (2007): Stability and flexibility of epigenetic gene regulation in mammalian development. Nature, 447, 425-432.

Rosenfeld, C.S. (2010): Animal models to study environmental epigenetics. Biol. Reprod., 82, 473-488.

Singh, P. and Thakur, M.K. (2014): Reduced recognition memory is correlated with decrease in DNA methyltransferase 1 and increase in histone deacetylase 2 protein expression in old male mice. Biogerontology, 15, 339-346.

Skinner, M.K., Anway, M.D., Savenkova, M.I., Gore, A.C. and Crews, D. (2008): Transgenerational epigenetic programming of the brain transcriptome and anxiety behavior. PLoS ONE, 3, e3745.

Suzuki, K., Ishikawa, K., Sugiyama, K., Furuta, H. and Nishimura, F. (2000): Content and release of bisphenol A from polycarbonate dental products. Dent. Mater. J., 19, 389-395.

Swank, M.W. and Sweatt, J.D. (2001): Increased histone acetyltransferase and lysine acetyltransferase activity and biphasic activation of the ERK/RSK cascade in insular cortex during novel taste learning. J. Neurosci., 21, 3383-3391.

Tang, W.Y., Morey, L.M., Cheung, Y.Y., Birch, L., Prins, G.S. and Ho, S.M. (2012): Neonatal exposure to estradiol/bisphenol A alters promoter methylation and expression of Nsbp1 and Hpcal1 genes and transcriptional programs of Dnmt $3 \mathrm{a} / \mathrm{b}$ and $\operatorname{Mbd} 2 / 4$ in the rat prostate gland throughout life. Endocrinology, 153, $42-55$.

Vandenberg, L.N., Chahoud, I., Heindel, J.J., Padmanabhan, V., Paumgartten, F.J. and Schoenfelder, G. (2010): Urinary, circulating, and tissue biomonitoring studies indicate widespread expo- sure to bisphenol A. Environ. Health Perspect., 118, 1055-1070.

Walker, D.M. and Gore, A.C. (2011): Transgenerational neuroendocrine disruption of reproduction. Nat. Rev. Endocrinol., 7, $197-$ 207.

Weaver, J.R., Susiarjo, M. and Bartolomei, M.S. (2009): Imprinting and epigenetic changes in the early embryo. Mamm. Genome., 20, 532-543.

Wolstenholme, J.T., Edwards, M., Shetty, S.R., Gatewood, J.D., Taylor, J.A., Rissman, E.F. and Connelly, J.J. (2012): Gestational exposure to Bisphenol a produces transgenerational changes in behaviors and gene expression. Endocrinology, 153, 3828-3838.

Wood, M.A., Kaplan, M.P., Park, A., Blanchard, E.J., Oliveira, A.M., Lombardi, T.L. and Abel, T. (2005): Transgenic mice expressing a truncated form of CREB-binding protein (CBP) exhibit deficits in hippocampal synaptic plasticity and memory storage. Learn. Mem., 2, 111-119.

Yaoi, T., Itoh, K., Nakamura, K., Ogi, H., Fujiwara, Y. and Fushiki, S. (2008): Genome-wide analysis of epigenomic alterations in fetal mouse forebrain after exposure to low doses of bisphenol A. Biochem. Biophys. Res. Commun., 376, 563-567.

Zhang, Q., Xu, X., Li, T., Lu, Y., Ruan, Q., Lu, Y., Wang, Q., Dong, F., Yang, Y. and Zhang, G. (2014): Exposure to bisphenol-A affects fear memory and histone acetylation of the hippocampus in adult mice. Horm. Behav., 65, 106-113.

Zawia, N.H. and Lahiri, D.K. (2012): Epigenetics: a paradigm shift in understanding Alzheimer's disease. Curr. Alzheimer Res., 9, 525-526.

Zhou, W., Liu, J., Liao, L., Han, S. and Liu, J. (2008): Effect of Bisphenol A on steroid hormone production in rat ovarian theca-interstitial and granulosa cells. Mol. Cell Endocrinol., 283, $12-18$. 